\title{
IDENTIDADES, SEXUALIDADES E DESEJOS MANIPULADOS NO "PONTO"1
}

\section{IDENTITIES, SEXUALITIES AND DESIRES MANIPULATED IN THE "POINT"}

\author{
Fabrício de Sousa Sampaio²
}

\section{RESUMO}

Nos últimos cinco anos, na esquina de uma das mais movimentadas avenidas da cidade de Sobral (CE), alguns jovens autoidentificados gays passaram a ensaiar a prostituição. Este artigo foi estruturado no propósito de discorrer acerca dos principais resultados de uma pesquisa de campo em andamento cujos objetivos iniciais foram: perceber os rituais de iniciação e estabelecimento construídos pelxs jovens num "ponto" de aparente prostituição; compreender os processos de construção e manipulação identitária sexual destxs, assim como refletir sobre a sexualidade juvenil sobralense. A incursão etnográfica utilizou como técnicas de pesquisa entrevistas abertas, depoimentos, conversas informais e observação participante. Butler, Bauman, Elias e Scotson, Hall,e Goffman foram xs principais interlocutorxs de sustentabilidade teórica da discussão que se segue. Os principais resultados preliminares da referida pesquisa podem ser compartilhados da seguinte maneira: a juventude como uma instância articuladora de (re)produção de sociabilidades e desveladora do caráter social construído pelas identidades sociais. Uma das conclusões advindas das observações feitas no "ponto" é a de que não só a manutenção da "fachada" é a base da interação social, mas que a identidade é ainda um exímio conceito para se compreender o processo interativo social. ${ }^{3}$

Palavras-chave: Estabelecimento ritual. Manipulação identitária. Práticas de interação. Sexualidades.

\footnotetext{
${ }^{1}$ Termo êmico para se referir à esquina de prostituição de "montadas" e travestis localizada na Avenida do Contorno, Bairro Campos dos Velhos da cidade de Sobral.

2 Doutor em Ciências Sociais. Técnico pedagógico da Coordenadoria de Desenvolvimento da Aprendizagem e da Escola (CODEA) pertencente à Secretaria de Educação do Estado do Ceará (Seduc/CE). E-mail: farcosousa @yahoo.com.br. Contato: (88) 99621-5800.

${ }^{3}$ Outra versão deste artigo foi publicada recentemente pela Revista Aceno em 2016.
} 


\begin{abstract}
In the last five years, on the corner of one of the busiest avenues in the city of Sobral (CE), some self-identified gay youths began to rehearse prostitution. This article was structured with the purpose of discussing the main results of an ongoing field research whose initial objectives were: to perceive the initiation and establishment rituals constructed by the young people in a "spot" of apparent prostitution; to understand the processes of construction and manipulation of their sexual identity, as well as to reflect on the juvenile sexuality of Sobral. The ethnographic incursion has used as research techniques: open interviews, testimonials, informal conversations and participant observation. Butler, Bauman, Elias and Scotson, Hall, and Goffman were the main theoretical support interlocutors of the following discussion. The main preliminary results of this research maybe shared as follows: youth as an articulating instance of sociabilities (re)production and as revealer of the social and constructed character of social identities. One of the conclusions of observations made in the "spot" is that not only the maintenance of the "facade" is the basis of social interaction, but that identity is still an excellent concept for understanding the social interaction process.
\end{abstract}

Keywords: Ritual establishment. Identity manipulation. Interaction practices. Sexualities.

\title{
O PONTO EM QUE O "PONTO" SE TRANSFORMA NO CAMPO DE PESQUISA
}

A cidade de Sobral - interior do Ceará, distante da capital Fortaleza em média $232 \mathrm{~km}$ - possui alguns prostíbulos mascarados na arquitetura de bar e determinados espaços de aglomeração e azaração gay, consensualmente estigmatizados pelas famílias tradicionais sobralenses, mas nem sempre pela juventude frequentadora ${ }^{4}$.

\footnotetext{
${ }^{4}$ As colaboradoras desta pesquisa enfatizaram os inúmeros discursos que ouviram acerca da "baitolagem" ou "safadeza" quando seus familiares se referiam a estes locais da cidade. Em contraposição, muitas
}

Inter-Legere - Revista de Pós-Graduação em Ciências Sociais da UFRN Natal RN, ISSN 1982-1662, nº 21, jul./dez. de 2017 
IDENTIDADES, SEXUALIDADES E DESEJOS MANIPULADOS NO "PONTO"

Fabrício de Sousa Sampaio

Nos últimos cinco anos, na esquina de uma das mais movimentadas avenidas da cidade, alguns jovens autoidentificados gays passaram a ensaiar a prostituição. Antes desta prática social, somente existiam dois "pontos" de prostituição de rua, dos quais por força da organização urbana engendrada pelo poder público via discriminação imposta pelas famílias tradicionais, um deles foi desativado, ficando apenas o outro que se localiza atualmente na saída da cidade para a capital Fortaleza. Localização estratégica tanto em relação às trabalhadoras do sexo, visto que seriam pouco incomodadas pela população sobralense, quanto para seus pretensos clientes, resguardando assim seu anonimato diante dos olhares julgadores da cultura. Desta maneira, esta prática social ficaria invisível para a grande maioria da população sobralense.

No entanto, por força das transgressões de alguns sujeitos sobralenses, o "ponto" da $O A B^{5}$ passa a se firmar na cidade e se constituir, diferente do ponto da "BR" ${ }^{\prime}$, num território de experimentação da prostituição de rua de jovens da classe popular e se torna reconhecido como tal. Com o passar dos anos, a frequência de jovens e adolescentes aumentou e a dinâmica de participação deste território particulariza-se. Relações de poder, demarcação espaço-temporal, exigência identitária e aprendizagens de códigos sociais passaram a constituir elementos de convivência interativa entre xs frequentadorxs do "ponto". Além disso, as "estabelecidas" exigiam certos rituais de iniciação e atribuição de personagens identitários aceitáveis às neófitas travestis ou michês ${ }^{7}$, como também controlavam a demarcação do território,

pessoas de seus círculos de convivência de variadas sexualidades não se importavam em frequentar estes bares, prostíbulos e as festas sobralenses estigmatizadas como gays.

${ }^{5} \mathrm{OAB}$ - Ordem dos Advogados do Brasil

${ }^{6}$ Sigla que designa um ponto de concentração de prostitutas na entrada da cidade, mais precisamente na BR-222.

${ }^{7}$ No início da etnografia do "ponto", percebi a frequência de alguns jovens na labuta da noite que eram semelhantes ao michê-bicha e ao michê-gay, classificações destacadas na obra de Perlongher (1987) que se referiam aos gays efeminados que vendiam o corpo. As colaboradoras denominavam esses michês de bicha ou "bicha machuda" que geralmente permaneciam em esquinas próximas ao "ponto". No período 
IDENTIDADES, SEXUALIDADES E DESEJOS MANIPULADOS NO "PONTO"

Fabrício de Sousa Sampaio

principalmente diante de outros prostitutos, travestis ou "montadas" ${ }^{8}$ que almejavam trabalhar naquela esquina. Para as colaboradoras, o termo "montar" designava o processo de construção de determinada mulher engendrado por um homem, caracterizado pelo uso de vestimentas e do fazer performático considerado feminino.

Utilizamos durante as reflexões sobre as dinâmicas do "ponto" a metáfora analítica de Elias e Scotson (2000), "estabelecidos" e "outsiders". Embora esta metáfora represente um binarismo oposicional excludente, ela será acionada em situações sociais que o tempo de frequência dxs jovens e as relações de poder existentes no "ponto" precisem ser destacados. Xs jovens que ainda não trabalham ou não participam internamente das negociações do sexo, corpo e prazer foram chamadxs neste trabalho de "outsiders". E as cofundadoras e suas "afilhadas" ${ }^{\text {" }}$ serão representadas pelo termo "estabelecidas".

Em 2010, o que mais chamou atenção neste "ponto" foi o aumento do número de jovens de faixas etárias diferentes, inclusive menores de idade, frequentando a esquina em dias específicos da semana. De início, poderíamos imaginar que todxs xs jovens que estavam no "ponto" se prostituíam. Todavia, a partir dos relatos, determinadas motivações foram identificadas: tornar-se travesti, procurar sexo casual e experimentar relações homoeróticas. Neste ínterim, foi possível afirmar que a dinâmica sociointerativa característica do "ponto" era complexa e precisaria ser investigada com mais afinco.

que antecedeu o término da observação participante, final de 2012, o "ponto da OAB" era frequentado apenas por travestis, "montadas" e gays que almejavam determinada experimentação social na prostituição ou no "viço": "montagens" para buscar sexo casual.

8 Adoto a diferenciação entre travesti e "montada" de acordo com os relatos das "estabelecidas" do "ponto". Travesti seria uma mulher fixa de pênis e a "montada", um jovem que construía uma determinada performance feminina apenas durante a noite para participar das dinâmicas do "ponto".

${ }^{9}$ Termo êmico que encerra o ato de vestir roupas de mulher de forma convincente (BENEDETTI, 2005)

10 As "estabelecidas" denominavam de "filhas" as jovens que seguiam os seus conselhos e dicas de "montagem" e estabelecimento no negócio do "ponto". 
IDENTIDADES, SEXUALIDADES E DESEJOS MANIPULADOS NO "PONTO"

Fabrício de Sousa Sampaio

Quais seriam então as motivações, os sentidos e as justificativas atribuídas por essxs jovens ao tentarem se apropriar de determinadas identidades, papéis e práticas reiteradas na esquina da OAB de Sobral? Que estratégias seriam engendradas na busca de satisfação de seus objetivos e desejos? O "ponto" se constitui numa espécie de "território de iniciação" para as práticas homoeróticas ou de prostituição? Estes jovens não estariam apenas experimentando as sexualidades e as identidades de gênero dissidentes das normatividades socioculturais? Vale ressaltar que nem todas essas problemáticas poderão ser aprofundadas no escopo deste trabalho. O método qualitativo foi escolhido como forma de compreender estas questões a fim de englobar uma quase totalidade dos ângulos que apresenta todo fato social em contraposição à aridez dos números - método quantitativo, que debilita os significados dos fatos (QUEIROZ, 1988). Entrevistas abertas, depoimentos, conversas informais e observação participante constituíram as técnicas de pesquisa acionadas.

O campo de pesquisa foi um "ponto" de aparente prostituição de rua localizado na avenida do contorno da cidade de Sobral (CE). Esse "ponto" situava-se na esquina da sede da OAB de Sobral no Bairro Campo dos Velhos. A singularidade deste "ponto" vinculava-se ao fato de ser supostamente um "ponto de iniciação" à prostituição de travestis e "montadas" na faixa etária dos dezesseis aos vinte e oito anos, visto que o outro ponto de prostituição estabelecido da cidade - intitulado pelxs colaboradorxs de "BR" frequentavam basicamente as travestis mais velhas e algumas mulheres. As colaboradoras da pesquisa pertenciam à classe trabalhadora e se reconheciam como gays. Elas serão identificadas no texto com os nomes escolhidos por elas: Raquel, Virna, Takeshita e Roseane. A identificação dos depoimentos no decorrer do artigo será feita de maneira aleatória para preservar o anonimato dxs jovens.

Conforme os primeiros depoimentos $\mathrm{dxs}$ quatro jovens, frequentavam em média cinco indivíduos regularmente durante a semana e outros três que 
IDENTIDADES, SEXUALIDADES E DESEJOS MANIPULADOS NO "PONTO"

Fabrício de Sousa Sampaio

"apareciam" esporadicamente. Além disso, a esquina era frequentada por alguns colegas das quatro primeiras jovens do "ponto". Estxs colegas, geralmente passavam longas horas observando e conversando com aquelas que "trabalhavam". Para as colaboradoras, estxs frequentadorxs observavam ora por curiosidade, ora tentando encontrar uma oportunidade para se firmar na esquina. A seguir são apresentadas algumas reflexões sobre a etnografia do "ponto" realizada entre os anos de 2010 e 2012. No primeiro momento, os rituais de interação e estabelecimento e as negociações de pertencimento identitário do "ponto" serão analisados. Em seguida, a manipulação identitária será compreendida como um mecanismo performático vinculado às interações sociais tanto para os sujeitos se estabelecerem quanto para se subverterem nos diferentes contextos culturais.

\section{RITUAIS DE INTERAÇÃO E ESTABELECIMENTO}

A demarcação socioterritorial do "ponto" foi efetivada basicamente por quatro jovens entre os anos de 2005 e 2007. Já o reconhecimento desta esquina como espaço de prostituição diante da sociedade sobralense se concretiza no ano de 2008, período em que se intensificava tanto a frequência de curiosxs jovens na busca por conhecer o cotidiano dxs praticantes do negócio do corpo quanto o número de homens que procuravam a satisfação sexual entre as jovens do "ponto".

Inicialmente, na etnografia do "ponto" foi possível vislumbrar quatro roteiros identitários que eram reproduzidos e exigidos pelas frequentadoras da esquina porque se relacionavam aos quatro modos de ser, fazer e estar no "ponto" das quatro primeiras jovens que, por pura diversão e busca de sexo 
casual, foram constituindo o "ponto". Existiam jovens e adolescentes ${ }^{11}$ que se identificavam com a travestilidade e procuravam vínculos de pertencimento identitário com a participante Raquel, a qual, dentre as outras, era a que praticava a prostituição na maior parte de suas interações na esquina.

As outras colaboradoras, geralmente, "montavam-se" para buscarem sexo. Em meio às interações sociais, Takeshita e suas apadrinhadas eram consideradas "caricatas ou sem estilo" (Raquel, 2011) ${ }^{12}$ em detrimento às outras participantes e diante das expectativas dos clientes. As suas "montagens" eram frequentemente definidas como "monstragem"13 pelo caráter não estereotipado, "bagunçado" e subversivo das expressividades femininas que esta colaboradora se apresentava em público. As participantes do "ponto", que somente procuravam sexo, eram, de certa maneira, hostilizadas: "esses viados vêm fazer de graça, por isso que tem bofe ${ }^{14}$ velho que não quer pagar e quando paga é uma mixaria, [...] eu quando noto que o viado quer só fazer isso, eu boto para correr logo, antes que se acostume" (Raquel, 2011). Vale enfatizar que mesmo com esses conflitos de interesses, Raquel relata que tem uma excelente relação de amizade com Takeshita e Roseane.

Existiam também aquelas participantes que faziam uma "montagem" um pouco mais refinada do gênero feminino e se preocupavam com algum ganho financeiro. Elas se identificavam com uma espécie de roteiro identitário representado pela frequentadora Roseane. Estas jovens não acionavam

\footnotetext{
${ }^{11}$ Utilizo como demarcação geracional entre adolescentes e jovens a definição êmica das colaboradoras do "ponto". Adolescente seria um indivíduo que possui menos de dezoito anos e jovem possuiria mais de dezoito anos.

${ }^{12}$ A identificação das colaboradoras será realizada com a inicial maiúscula e as outras letras minúsculas, seguida do ano de coleta do relato, para se diferenciar da formatação da ABNT.

13 Paródia do ato de "montar" direcionado a Takeshita e a suas seguidoras. A "monstragem" representava uma "montagem" feminina que utilizava algumas peças masculinas adaptadas e que assumia a imagem de um monstro por não ser possível se enquadrar nas vestimentas estereotipadas masculinas e femininas consensualmente aceitas como "normais" para determinados frequentadorxs da esquina.

${ }^{14}$ Termo êmico para designa homens que performam o ideal de virilidade macho que são ativos com gays e mulheres. Para Raquel, eles não são considerados homossexuais por eles, porque não tem trejeitos e não compartilham de uma identidade gay ou possuem uma vida heterossexual, ou seja, namoram mulheres, possuem filhos, não possuem amigos gays e nem transitam por lugares reconhecidamente LGBT.
}

Inter-Legere - Revista de Pós-Graduação em Ciências Sociais da UFRN Natal RN, ISSN 1982-1662, no 21, jul./dez. de 2017 
IDENTIDADES, SEXUALIDADES E DESEJOS MANIPULADOS NO "PONTO"

Fabrício de Sousa Sampaio

modificações corpóreas a fim de melhorar sua performance feminina tal como as participantes vinculadas a Raquel. Um último grupo se identificava com a frequentadora Virna. Estas participantes engendravam incipientes alterações corpóreas com intuito de se aproximar de uma representação feminina, entretanto ora buscam dinheiro, ora não cobram nada por seus serviços sexuais. E mesmo com as visíveis modificações do corpo - que aparentemente poderia conjecturar ser uma tentativa de se tornarem travestis - Virna e suas "afilhadas" eram enfáticas em afirmarem que não pretendiam se tornar travestis, apenas se "montavam".

Neste sentido, foi possível classificar temporariamente, a título de análise, esses quatro roteiros identitários a fim de operar uma tênue diferenciação entre xs frequentadorxs do "ponto". Não se trata aqui de grupos sociais hermeticamente distintos numa mesma esquina, principalmente, porque depois de estabelecidas, as participantes passam a interagir entre si como se não houvesse nenhuma distinção aparente, embora no ato do negócio do corpo, dependendo da finalidade - ganho monetário e/ou busca por sexo - e das formas estilísticas de ser e estar no "ponto", ocorra certas divergências. Assim, os arranjos identitários que ora as definem podem não representar as suas identificações abertas, múltiplas e interconectas que ocorrem permanentemente.

De acordo com os relatos, fazer amizade, possuir uma estética corporal compatível, saber se vestir e ter simpatia foram os quesitos imprescindíveis enumerados para tentar se estabelecer no "ponto". Xs jovens "outsiders", mesmo performando esses quesitos, nem sempre conseguiam se estabelecer. Os corpos desviantes a esse enquadramento eram estigmatizados:

Tem bicha feia que quer se montar e descer, mas não tem jeito pra coisa e faz tempo que me atenta pra eu ajudar. Não vou ajudar, primeiro porque o viado não se ajuda, é gorda, fica ridícula nas roupas para descer que tem que mostrar o corpo e até hoje tem raiva de mim, e eu ligo. (Raquel, 2011) 
IDENTIDADES, SEXUALIDADES E DESEJOS MANIPULADOS NO "PONTO"

Fabrício de Sousa Sampaio

Os primeiros contatos com o "ponto" de um/uma "outsider" ocorrem sempre com "a desculpa de que perguntar por 'alguma gaya' que anda aqui ou porque realmente já conhece alguma da gente e quer vir conversar" (Raquel, 2011). O termo "gaya" parece identificar um gay cujo efeminamento é considerado um exagero por Raquel. Nem sempre essa conversa é bem-vinda principalmente se for depois das dez da noite porque é o período que começa a frequentar os possíveis clientes: "tem bicha que vem conversar besteira e faz até a gente perder cliente, por isso conversou demais, eu debando logo" (Takeshita, 2011). Dependendo da simpatia e se as "estabelecidas" considerarem que o jovem tem vontade de aprender certos códigos, não vai atrapalhar os negócios e que não quer apenas "fazer de gaiata, porque não arranja ninguém para transar" (Takeshita, 2011), o/a "outsider" passa a ser "afilhadx" por uma das "estabelecidas" e a ser socializadx em relação aos códigos de convivência do "ponto" através de aconselhamentos, dicas e roteiros de comportamentos a serem adotados na esquina.

No processo de busca por apadrinhamento objetivado pelxs curiosxs que circundavam o "ponto", as interações iniciais face a face eram cuidadosas e decisivas para a construção do estabelecimento, de acordo com alguns "outsiders". Neste sentido, estes contatos iniciais eram caracterizados pela preservação de uma "fachada" consistente a "linha" ${ }^{15}$ desempenhada pelxs jovens que estavam participando deste encontro social. Entretanto, esta manutenção da fachada seria avaliada durante a participação dxs neófitos em processo de estabelecimento, visto que:

\begin{abstract}
A fachada pessoal e a fachada dos outros são construtos da mesma ordem, são as regras do grupo e a definição da situação que determinam quantos sentimentos devemos ter pela fachada e como esses sentimentos devem ser distribuídos pelas fachadas envolvidas. (GOFFMAN, 2011, p.14).
\end{abstract}

\footnotetext{
15 "padrão de atos verbais e não verbais com o qual ela expressa sua opinião sobre a situação, e através disto, sua avaliação sobre os participantes, especialmente ela própria” (GOFFMAN, 2011, p.13).
} 
IDENTIDADES, SEXUALIDADES E DESEJOS MANIPULADOS NO "PONTO"

Fabrício de Sousa Sampaio

Os "sinais externos de orientação e envolvimento" que poderiam assassinar a fachada ou deixar xs "outsiders" com "fachada errada" ou "fora da fachada"16 e determinar o futuro do processo interativo na esquina eram: as olhadelas consideradas reprovativas com relação ao figurino que as "estabelecidas" estavam vestindo; os gestos, posicionamentos e até enunciados verbais que emitissem reprovação ou ojeriza quanto aos comportamentos exercidos no "ponto" ou fora dele; e demonstração de qualquer aversão às práticas engendradas durante a interação com os clientes e/ou, especificamente, no decorrer da relação sexual, por exemplo, "dar um boa noite cinderela no boy e roubar ele" (Virna, 2012).

A preservação da fachada é uma necessidade para se obter a aceitação mútua: característica estrutural básica da interação, especialmente da interação em conversas face a face típicas dos encontros entre "estabelecidas" e "outsiders", prostitutos e clientes, como qualquer jovem e sua eminente "presa" sexual ou parceiro amoroso. Em suma, quando uma pessoa realiza a preservação da fachada, junto com seu acordo tácito de ajudar as outras a realizar a delas, isto representa sua disposição em obedecer às regras básicas da interação social. Eis o símbolo de sua socialização enquanto um participante da interação (GOFFMAN, 2011, p.37).

No processo de estabelecimento, as recém-iniciadas eram orientadas por suas madrinhas fundamentalmente nas vestimentas, na maquiagem, nas posturas corporais e nas formas de abordagens com os clientes. O grau de exigência pela qualidade e o conteúdo destes aspectos se diferenciavam de acordo com os grupos identitários vinculados às quatro cofundadoras do "ponto". Raquel era a mais exigente nestes quatro quesitos a ponto de desistir

\footnotetext{
${ }^{16}$ Pessoa com a fachada errada traz "alguma informação sobre seu valor social que não pode ser integrada mesmo com esforço, com a linha que está sendo mantida por ela”. E pessoa que está fora da fachada "participa de um contato com os outros sem ter uma linha pronta do tipo que esperamos que participantes de tais situações tenham" (GOFFMAN, 2011, p.16).
} 
IDENTIDADES, SEXUALIDADES E DESEJOS MANIPULADOS NO "PONTO"

Fabrício de Sousa Sampaio

facilmente das suas "afilhadas", porque "tem bicha que quer ser trava ${ }^{17}$, mas não aprende a se vestir, nem se maquiar, além de não saber andar no salto, andando com as pernas abertas e toda torta" (Raquel, 2011).

Geralmente, essxs "outsiders" que não conseguiam com Raquel, buscavam se identificar com as exigências performáticas de Takeshita ou Roseane. Takeshita relatava que não se preocupava com um refinamento das vestimentas femininas. Às vezes nem sapatos femininos utilizava. Ela fazia combinações de roupas insuportáveis para Raquel, por exemplo, uma saia que vira miniblusa complementada por um short visivelmente masculino e uma sandália havaiana. Com relação à maquiagem, geralmente utilizava apenas um batom e uma base facial cor da pele. Não se preocupava em mimetizar atributos considerados femininos por concepções estereotipadas de gênero das colaboradoras tais como a delicadeza, afinação da voz, tratamento carinhoso e sutil direcionado aos clientes e manejo bem-sucedido da bolsa e da peruca. Brincando com a performance de gênero estereotipada, Takeshita e suas "filhas", buscando sexo e não a venda de suas habilidades sexuais, colocavam em risco constante a imagem do "ponto" como espaço social de ganho financeiro a partir da venda do sexo, de acordo com o relato de Raquel e de Virna.

Roseane e suas "afilhadas" pareciam se enquadrar numa fase transitória para a concepção de travestilidade, sustentada por Raquel, no tocante à busca pelo refinamento das vestimentas, maquiagem e aproximações com uma imagem de mulher a ser posta em prática no trato com o cliente. Estas "estabelecidas" objetivavam a venda de seus corpos, entretanto, em algumas vezes, de acordo com os seus relatos, o desejo sexual imperava e a moeda de troca passava a ser somente a obtenção do prazer. Porém, elas cuidavam para que estas fugas do ato comercial não se tornassem repetitivas a fim de

\footnotetext{
${ }^{17}$ Termo êmico para travesti.
} 
IDENTIDADES, SEXUALIDADES E DESEJOS MANIPULADOS NO "PONTO"

Fabrício de Sousa Sampaio

comprometerem a representatividade do "ponto" como um espaço de prostituição de travestis e "montadas" e não como um espaço de "pegação" entre homossexuais que se "montam" e os não montados.

Virna e suas "filhas" possuíam um posicionamento dentro do "ponto" que escapava às definições e aos enquadramentos. Ora se refinavam em suas performances femininas se aproximando de Raquel, ora se caricaturavam se aproximando de Takeshita. Segue o relato de Virna.

Às vezes paro e acho legal o que um travesti está fazendo e aí passo a imitá-lo, depois vejo que não faz sentido, aí paro e vou dar uma de boy na festa do motel ${ }^{18}$ para conseguir linha ${ }^{19}$. Quando volto no ponto me dá vontade de descer ${ }^{20}$, aí me arrumo e me realizo. Mas não me passa na cabeça botar peito, tomar hormônio, também não quero ficar musculosa porque quero me sentir feminina para os boy. (Roseane, 2011)

Este grupo de jovens era pequeno e tinham uma menor frequência no "ponto". A maioria buscava o estabelecimento que era dificultado pelas outras participantes principalmente por sua marca performática desviante, cambiante, sinuosa, transitória e estranha com relação às performances femininas valorizadas na esquina. Roseane manipulava as identidades e suas fachadas constitutivas com uma capacidade não observada entre as outras participantes do "ponto". Parecia que a redefinição de seu objeto de desejo era intensa e, ao mesmo tempo, situada no calor dos eventos sociais que participava. Ela e suas "filhas" demonstravam exímia capacidade de constituir e desapegar de identidades socioculturais que conscientemente percebiam serem exigidas e aceitáveis em variadas interações humanas.

\footnotetext{
${ }^{18}$ De acordo com as colaboradoras, mais precisamente no ano de 2012, intensificam-se festas eletrônicas gays em suítes de motel da cidade de Sobral (CE).

19 Termo êmico para uma relação sexual casual ou uma negociação do corpo.

${ }^{20}$ Termo êmico para fazer "programa" ou se dirigir ao "ponto" e se preparar para o negócio do sexo.
} 
IDENTIDADES, SEXUALIDADES E DESEJOS MANIPULADOS NO "PONTO"

Fabrício de Sousa Sampaio

\section{MANIPULAÇÃO IDENTITÁRIA}

De caráter evasivo e escorregadio, as identidades na pós-modernidade estão flutuando, algumas escolhidas por nós e outras impostas pelos que estão ao nosso redor. Elas são para usar e exibir, não para armazenar. No cenário no qual impera as incertezas, a velocidade, a descartabilidade, a insegurança e a liquidez, prender-se ou aventurar-se na solidificação de única identidade é mais do que arriscado (BAUMAN, 2005).

A identidade objetiva deve suturar o sujeito à estrutura social a fim de estabilizá-lo nos mundos culturais que ele habita (HALL, 2006). A fim de pertencer ao "ponto" e ser reconhecidx por seus pares e futuros clientes era necessário que as participantes usassem determinada identidade que era imposta pela dinâmica social. Neste ínterim, mostrou-se de suma importância perceber como estes sujeitos vão construindo suas identidades individuais e/ou de preferência em constante batalha com as identidades atribuídas cuja definição se dá pela troca, negociação, conflito e interação com os outros e os respectivos contextos sociais (WOODWARD, 2008) ${ }^{21}$.

Pode-se considerar que as identidades humanas são construções de suturação social constituídas pelo conhecimento e reconhecimento dos mecanismos regulares de manter as fachadas necessárias em encontros sociais comuns os quais exigem ajustadas "imagens do eu delineada em termos de atributos sociais aprovados" (GOFFMAN, 2011, p.14) em cada interação face a face que venha a ocorrer.

Butler (2010) problematiza a construção dos gêneros e das identidades centrando-se em duas instâncias cruciais: 0 falocentrismo e a

\footnotetext{
${ }^{21}$ Neste artigo, as identidades assumidas e as atribuídas pelo arbitrário sociocultural são pensadas numa perspectiva binária e oposicional. Vale ressaltar que a noção de "performatividade de gênero" da filósofa Judith Butler, bem como sua defesa por uma subversão das identidades, passa por sua concepção de identidade como constructo que interconecta subjetividade e normas sociais. A subjetividade como singularidade dos sujeitos que são constituídos pelas normas. Por isso, a subversão precisa ocorrer no interior das normas e nunca apartada completamente delas.
} 
IDENTIDADES, SEXUALIDADES E DESEJOS MANIPULADOS NO "PONTO"

Fabrício de Sousa Sampaio

heterossexualidade compulsória. Tornou-se "impossível separar a noção de 'gênero' das interseções políticas e culturais em que invariavelmente ela é produzida e mantida" (BUTLER, 2010, p.20). A autora exerce uma crítica genealógica investigando as apostas políticas das categorias de identidade entendidas como efeitos de instituições, práticas e discursos cuja origem é múltipla e difusa. Ela destaca o status construído do gênero e até do sexo, pois "talvez o sexo sempre tenha sido o gênero, de tal forma que a distinção entre sexo e gênero se revela absolutamente nenhuma" (BUTLER, 2010, p.25). O gênero não pode ser mera inscrição cultural, "tem de designar também o aparato mesmo de produção mediante o qual os próprios sexos são estabelecidos" (BUTLER, 2010, p25).

Em outras palavras, a identidade de gênero inteligível vinculada a uma matriz cultural exige que certos tipos de identidade não possam existir "aquelas em que o gênero não decorre do sexo e aquelas em que as práticas do desejo não 'decorrem' nem do 'sexo' nem do 'gênero'” (BUTLER, 2010, p.39). A existência dessas identidades inteligíveis dissemina matrizes rivais e subversivas de desordem de gênero (BUTLER, 2010). O gênero verdadeiro é uma fantasia. Ele não pode ser verdadeiro nem falso, mas "somente produzido como efeitos da verdade de um discurso sobre a identidade primária e estável" cuja ilusão de núcleo interno é criada a partir da articulação de atos, gestos e desejos postos em prática e que discursivamente se propõe a regular a sexualidade nos termos de uma heterossexualidade reprodutora (BUTLER, 2010, p.195).

O gênero é um ato performativo e a base da identidade é a repetição estilizada de atos ao longo do tempo. Assim, a identidade permanente é uma construção politicamente tênue de efeito fantasístico (BUTLER, 2010, p.201). A performance realiza-se com objetivo estratégico de manter a estrutura binária de gênero. Neste sentido, a identidade de gênero pode ser concebida: 
outras imitações e que, em conjunto, constroem a ilusão de um eu de gênero primário, interno marcado pelo gênero, ou parodiam o mecanismo dessa construção. (BUTLER, 2010, p.197).

As performances de gênero ensaiadas pelxs jovens no "ponto" possuíam certa legitimidade de sua diversidade porque as quatro jovens cofundadoras atuavam para controlar e predizer os roteiros identitários inteligíveis. Entretanto, existia uma matriz cultural de gênero feminino que funcionava para a construção das "mulheres" que participavam do negócio do sexo. A mulher jovem, bem perfumada, que não usa maquiagem exagerada, que se veste bem, faz boas combinações de roupas as quais acentuam as curvas de seus corpos e que se movimente de forma delicada, carinhosa, porém decidida e "cheia de si" era a referência performativa feminina utilizada nas construções das mulheres das participantes do "ponto". Porém, no ato das "montagens" dessas "mulheres", as jovens se deparavam com as construções socioculturais já elaboradas dos respectivos grupos identitários para depois negociarem o tipo de "mulher" que representariam no "ponto". Entre as participantes do "ponto" se percebia uma reiterada busca por prazer sexual mesmo que o "ponto" se caracterizasse geralmente como um território de prostituição de rua. Entre Virna e Roseane, a máxima prevalecia de que "só cobro se o bofe for feio e, se for mais feio, ainda eu aumento o preço" (Virna, 2011). Uma das singularidades desta esquina era a prática sociointerativa de se "montarem" e tentarem se identificar com as performances femininas exibidas pelas cofundadoras para engendrar suas buscas por sexo ou "viço" 22 , nos termos das colaboradoras. Mas por que era preciso se "montar" para conseguir um parceiro sexual entre os pretensos clientes do "ponto"?

\footnotetext{
22 Prática de quem quer apenas transar, satisfazer seus desejos sexuais de acordo com as escutas da etnografia. Algumas jovens manipulavam suas performances na esquina com a identidade de prostituta, mas não cobravam para manter relações sexuais. Utilizavam a prostituição como fachada, na opinião das colaboradoras.
} 
IDENTIDADES, SEXUALIDADES E DESEJOS MANIPULADOS NO "PONTO"

Fabrício de Sousa Sampaio

Uma das razões possíveis para o questionamento anterior foi encontrada pelo desvelamento de uma das normas de estruturação do "ponto": para se estabelecer nesta esquina, era necessário performar uma mulher para se prostituir. $\mathrm{O}$ "ponto" foi constituído socialmente como esquina de prostituição de travestis, embora entre as participantes existissem as "montadas" que geralmente passavam uma temporada na esquina. Durante a interação com as participantes, apenas duas jovens se identificavam como travestis. As outras sete frequentadoras reiteravam que se "montavam" para participar do "ponto" e nas suas vidas sociais se identificavam como gays.

Outra razão era a interdição constante das "estabelecidas". Elas não aceitavam michês, seja gay ou não, ou por temerem perder suas clientelas, ou por promoverem certa descaracterização do espaço social constituído. Vale destacar que o temor de perda de clientela - cuja maioria era constituída por gays mais velhos ou como elas chamavam de "mariconas" - era, de certa maneira, representada pela concordância entre as colaboradoras de que, na existência desses michês, as travestis e as "montadas" não eram procuradas no negócio do sexo. Raquel relatava que na concorrência com as "bichas machudas", as "montadas" acabavam perdendo, pois as "mariconas" buscavam preferencialmente serem penetradas no ato sexual, embora em quase todos os seus programas, Raquel mantinha relações com estes clientes como ativa também. As quatro colaboradoras não gostavam dessas "bichas machudas", porque além de "roubarem nossas linhas" (Raquel, 2011), elas praticavam sexo sem cobrar. Mesmo assim, não era simplesmente se "montar" de qualquer forma que o jovem conseguiria manter sua fachada e ser aceito entre as participantes da esquina, era necessária uma performance identitária. A performance funcionaria como um ato ritualístico de demonstrar publicamente os atributos vinculados a determinada identidade de gênero, ou melhor, das identidades legitimadas para estarem no "ponto": determinadas posturas diante dos clientes; comportamentos típicos durante a convivência entre as 
IDENTIDADES, SEXUALIDADES E DESEJOS MANIPULADOS NO "PONTO"

Fabrício de Sousa Sampaio

participantes do trabalho sexual na esquina; e a estética construída de determinada mulher.

Vale enfatizar que as participantes operavam com a seguinte diferenciação. Os clientes era uma categoria de frequentadores constituída por "mariconas" ou "coroas enxutos" que pagavam por seus serviços sexuais. E parceiros sexuais ou "bofes" eram constituídos por homens não "afeminados" e na faixa etária limite até os trinta anos que satisfaziam os desejos sexuais das "estabelecidas" e dxs "outsiders". Regularmente, dependendo do dia de trabalho e do cotidiano das jovens, a fronteira desta distinção se desfazia: "tem dia que não dá ninguém e dou graças a deus ter um caldo ${ }^{23}$ ou um bofe velho para pelo menos eu gozar" (Takeshita, 2012). Entretanto, percebia-se que as jovens, principalmente Takeshita e Roseane, desobedeciam às normas de estruturação do "ponto" e não eram retaliadas pelas demais. Em outros termos, manipulavam suas identidades conforme seus desejos e nem por isso eram rechaçadas pelas outras participantes da esquina do prazer e do negócio do corpo.

Parece que um exímio manipulador identitário era aquele indivíduo que, além de conhecer e preservar suas fachadas de acordo com os espaços sociais que participava, ele conseguia, a partir da construção de representações de ser, estar e sentir adaptáveis àqueles determinados espaços, manipular essas mesmas representações para atingir seus objetivos. $\mathrm{E}$, dependendo dos espaços, e por manobras discursivas e/ou posturais, engendrar mutações nas próprias representações das quais ele se valeu para iniciar determinada interação. Em termos, este manipulador pode se assemelhar a um ator da vida cotidiana. A manipulação identitária performances, manutenção de fachadas, redefinição do desejo e reelaboração

\footnotetext{
${ }^{23}$ Termo utilizado entre as jovens para designar um homem jovem pobre, que se veste mal e atua nos crimes.
} 
IDENTIDADES, SEXUALIDADES E DESEJOS MANIPULADOS NO "PONTO"

Fabrício de Sousa Sampaio

dos objetivos - talvez necessite de um corpo em permanente modificação. Criticando o gênero performativo de Butler, Preciado (2008) defende um gênero protético atrelado à materialidade do corpo. Assim, a performance engendrada pelo sujeito a fim de atingir a unidade heteronormativa sexo-gênero-desejo somente seria eficaz através de um corpo sempre tecnicamente modificado, conforme os modelos inteligíveis de corpo-gênero-sexo-desejo. Em suma, já que não existiria uma essência no corpo - apenas seu aparato biológico de nascimento pronto a ser transformado - a gestão corpórea constituiria na estratégia subjetiva fundante tanto para conformação aos gêneros inteligíveis definidos pelas normas socioculturais quanto para a subversão de gênero e uma manipulação identitária bem-sucedida.

O corpo materializa um conjunto de poderes culturais de subjetivação como também possibilidades estratégicas subjetivas de resistência. Interessante notar que os corpos excluídos e abjetos de cada agrupamento do "ponto", ao perceberem as possibilidades de se tornarem "estabelecidos", manipulavam suas performances para atingir esse objetivo. Raquel e Virna excluíam de suas interações na esquina os corpos obesos, acima do peso e musculosos "afeminados". Takeshita estigmatizava os corpos que estavam fazendo alterações tais como a ingestão de hormônios femininos, aplicações de silicones, ou seja, que estavam se assemelhando a uma identidade travesti. Já Roseane geralmente não estigmatizava as outras frequentadoras a partir dos critérios acima. Por estar familiarizada com as ambiguidades, as resistências e os investimentos criativos, esta participante e suas "filhas" eram as "montadas" mais criticadas, perseguidas e/ou abjetadas por quase todas as outras participantes.Poderíamos considerar que as "montadas" Takeshita, Virna e Roseane exercem manipulação identitária para continuarem no "ponto".

Embora Takeshita parecesse estar apenas brincando de se vestir como mulher para conseguir sexo, ela deveria possuir mecanismos performáticos que a possibilitasse continuar estabelecida no "ponto" e conseguir também seus parceiros sexuais. De forma geral, a manipulação identitária pode ser 
IDENTIDADES, SEXUALIDADES E DESEJOS MANIPULADOS NO "PONTO"

Fabrício de Sousa Sampaio

pensada como um mecanismo performático dos sujeitos de sutura com as específicas normatividades que os contextos culturais determinados possuem.

Analisada como um grande palco pelos teóricos da performance, tais como Erving Goffman e Richard Schechner, as interações sociais seriam engendradas por sujeitos-atores que demonstram a cada microrrelação com os outros o seu potencial de manipulador identitário. Xs "jovens nem sempre se enquadram" nas prescrições sociais (PAIS, 2006). Elxs parecem constituir, historicamente, o motor social de produção e reprodução de sociabilidades e desveladorxs do caráter social e construído das identidades socioculturais. As "culturas juvenis são vincadamente performativas" (PAIS, 2006, p. 7) e objetivam ultrapassar limites e fronteiras estabelecidas. $E$ nestes atos performativos de interação com os outros, xs jovens asseguram "expressividades de natureza identitária: de buscas de si através do outro" (PAIS, 2006, p.18) por meio de "farsas do disfarce".

As performatividades juvenis facilitadas pelas "farsas do disfarce" caracterizadas pelo jogo preservacional das fachadas concorrem para um processo manipulatório de identidades bem-sucedido. Os depoimentos juvenis comprovaram uma manipulação de performances principalmente entre as frequentadoras do "ponto", na abordagem com os clientes e possivelmente durante as experiências de vida social fora do "ponto".

Pode-se afirmar, pelas falas das entrevistadas, que a manipulação identitária seria o investimento político juvenil por excelência na busca de si nos espaços sociais em que participavam. Não apenas no "ponto", mas fundamentalmente em contextos culturais - governados pela heteronormatividade ${ }^{24}$ - a juventude obedeceria aos seus desejos por meio deste investimento porque talvez tivesse descoberto os regimes de poder envolvidos em torno das identificações do gênero e da sexualidade. Em outros

\footnotetext{
${ }^{24}$ Termo de Michael Warner (1991) que expressa expectativas, demandas e obrigações sociais a fim de operar uma naturalização da heterossexualidade.
} 
IDENTIDADES, SEXUALIDADES E DESEJOS MANIPULADOS NO "PONTO"

Fabrício de Sousa Sampaio

termos, as jovens não incorporavam para sempre identidades projetadas pelos arranjos culturais nos mais variados espaços que eles interagiam e sim manipulavam o seu 'guarda-roupa de 'eus múltiplos', num carrossel de múltiplas representações" (PAIS, 2006, p.19) para atingir seus objetivos e desejo não somente no amor, no sexo, mas também nas variadas esferas de sociabilidade.

É notório na fala das jovens como o desejo sexual era afetado pelo regime representativo do gênero. A estrutura binária do sexo e do gênero - ser homem-macho e ser mulher-fêmea - construídos socialmente para controlar as sexualidades e, sobretudo o aparecimento de identificações dissidentes, afetava as escolhas sexuais e constituíam as referências para o investimento manipulatório necessário na busca pelo parceiro sexual ou, no caso específico, a simpatia com os clientes.

Em lugares sociais em que frequentavam gays e simpatizantes, as jovens utilizavam suas fachadas, disfarces e manipulações de acordo com as expectativas de determinado contexto cultural, as demandas e as exigências sociais já descobertas por eles:

\footnotetext{
Parece que os gays de hoje só querem saber da bicha machuda, bombada, musculosa. Para eu conseguir alguém nestes lugares onde gay vai, como bar, boate e outros lugares, a gente precisa dar uma de boy, porque senão a gente não consegue nada, mesmo sabendo que é um bando de passiva se fazendo de boy. (Roseane, 2011).
}

A ditadura binária do gênero controla os relacionamentos homossexuais. No relato acima, Roseane afirma exercer sua manipulação identitária e performa um homem másculo ou boy para ser considerado como objeto de desejo. Entre as jovens do "ponto", os atributos oposicionais e culturais masculinos e femininos eram destacados tanto nos discursos que falavam da relação sexual quanto aqueles que identificavam posicionamentos das jovens nas interações face a face dos encontros sociais que antecediam e procediam a prática do sexo. 
IDENTIDADES, SEXUALIDADES E DESEJOS MANIPULADOS NO "PONTO"

Fabrício de Sousa Sampaio

O "gay-macho", possuidor do desejo homossexual, era aquele, nos termos das colaboradoras, que performava o homem-macho, ou seja, gostava de beber nos bares com amigos; jogava e adorava futebol; gostava de forró; ficava ou mantinha relações com mulheres; falava grosso; andava "como homem" e não era passivo na relação sexual com outro homem. Este indivíduo além de ser o "sonho de consumo" entre os homossexuais estabelecidos e "outsiders" do "ponto", era a referência para a construção das fachadas e disfarces necessários para se manter "no armário" de muitos gays da cidade de Sobral, de acordo com as colaboradoras.

A "bicha-machuda" que as colaboradoras falavam simbolizava a manipulação performática executada por algumas "bichas" tendo como referência esse "gay-macho". A "bicha-machuda" representava um gay que era ativo, possuía os atributos masculinos e por isso satisfazia o desejo de alguns

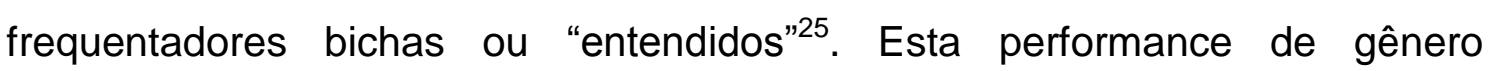
encerrava a fantasia de se relacionarem com corpos homens e não com indivíduos considerados bichas as quais carregam uma desvalorização no "ponto" por serem enquadradas como passivas, "chuponas" ou "mulherzinhas" (Takeshita, 2012).

Percebe-se que a heteronormatividade atravessava as relações homossexuais do "ponto" de forma decisiva e estigmatizadora. Se o homossexual possuísse os chamados trejeitos femininos, ele era considerado passivo e consumidor de objetos culturais tidos como gay, tais como gostar de música eletrônica. Reconhecido como uma "bichinha", este indivíduo desempenharia a função de mulher na relação sexual: ser submissa, sensível e passiva apenas. Em determinado momento da etnografia, Raquel revelou a possibilidade de fissuras desta correlação entre ativo/passivo, macho/fêmea e boy/bicha entre quatro paredes durante a relação sexual: "teve um dia que dei

\footnotetext{
${ }^{25}$ Termo utilizado pelos jovens do "ponto" para designar os gays que não possuem trejeitos, mas que não se preocupam nem em se tornar uma "machuda" ou de vez em quando "desmunhecar".
} 
IDENTIDADES, SEXUALIDADES E DESEJOS MANIPULADOS NO "PONTO"

Fabrício de Sousa Sampaio

uma de ativa para um bofe escândalo, foi o melhor programa que tive até hoje, tanto que nem cobrei" (Raquel, 2011). Embora o cliente tenha sido passivo na relação sexual, ele representava um homem-macho e, por isso, não foi considerado por Raquel como gay e sim como "bofe".

Assim, é possível afirmar que diante destes relatos do "ponto" que a sexualidade entre os homens estaria normatizada pelo binarismo oposicional de gênero que também seria identificado pelas posições ativo/passivo durante as práticas sexuais, o homossexual seria definido por sua performance de gênero vinculada aos trejeitos femininos e, por conseguinte, seria passivo; e o heterossexual seria definido por sua performance máscula, embora mantivesse relações amorosas e/ou sexual com outros homens. E, mesmo sendo passivo no ato sexual e se não possuísse uma performance trejeita, ele seria considerado heterossexual. No episódio acima percebe-se que o abjeto feminino - passividade homossexual - era positivada pelo corpoperformatizado masculino no exterior social. Mesmo que o indivíduo fosse passivo - atributo diferenciador, acionado pelas colaboradoras, entre bichas e machos - ele ainda continuaria homem por imaginar que ele habitava no mundo heterossexual cujos requisitos foram citados anteriormente. Além disso, o seu corpo legitimava também sua performance masculina: não possuía trejeitos e voz fina; "sem gíria de viado e fazia academia" (Raquel, 2011).

Em suma, mesmo que o "ponto" simbolizasse um espaço de manipulação identitária, sexual, do gênero e dos desejos, entre muitas participantes estas manipulações engendradas eram capturadas pelos valores heteronormativos de classificação, legitimação e hierarquização das próprias manipulações das outras frequentadoras do "ponto": parecia que para cada grupo ou indivíduo existia um ponto limite de manipulação possível e aceitável e, caso este limite fosse ultrapassado, o desestabelecimento do "ponto" poderia ser a consequência direta. 
IDENTIDADES, SEXUALIDADES E DESEJOS MANIPULADOS NO "PONTO"

Fabrício de Sousa Sampaio

\section{CONSIDERAÇÕES FINAIS}

Uma das afirmações importantes advindas das observações feitas no "ponto" é a de que não apenas a manutenção da fachada é a base da interação social, como também a identidade continua sendo uma exímia categoria para se compreender o processo interativo social porque ela encerra um conjunto elaborado de fachadas necessárias para aceitação em encontros face a face e assim os indivíduos articulem seus objetivos e interesses contextualizados. As identidades constituem negociações para significar a própria existência social e também se mover no terreno arriscado das subversões das ordenações sociais via manipulação performática das padronizações culturais de gênero e sexualidade vigentes. Pela capacidade $\mathrm{dxs}$ jovens de descobrir o caráter regulador e controlador das normatividades culturais, a manipulação identitária constitui assim uma das mais destacadas estratégias de convivência nos mais variados espaços sociais. A ditadura binária de gênero ainda impera nas interações sociais independente do teor sexual e afetivo. Percebeu-se que 0 desejo sexual se mostrava afetado pelas posições estereotipadas, oposicionais e construídas socioculturalmente de ser homem ou de ser mulher assumidas durante $o$ ato sexual do que a definição ativo e passivo na relação sexual: "posso estar subindo pelas paredes para dar [...], mas se a criatura der uma de bicha ou desisto de fazer, ou se for bonitinha eu como" (Roseane, 2011).

O "ponto" se constituía numa espécie de território de iniciação tanto para as práticas homossexuais quanto para experimentação dos negócios do corpo, principalmente porque o espaço urbano sobralense não facilitava os processos de busca homossexual por parceiros sexuais: não existiam espaços para "pegação" ou deriva homossexual tradicionalmente reconhecidos, tais como boates, saunas, bares, "cinemão", ou locais públicos de "pegação", como praças, pontes ou banheiros públicos, nos termos das colaboradoras. O que se sustenta atualmente na cidade de Sobral (CE) são as festas eletrônicas mensais em clubes que pelo marketing, principalmente através das mídias 
IDENTIDADES, SEXUALIDADES E DESEJOS MANIPULADOS NO "PONTO"

Fabrício de Sousa Sampaio

sociais, atrai o público gay. Estas festas foram consideradas pelas colaboradoras como os únicos espaços de paquera entre homens da cidade. As considerações feitas acerca da manipulação identitária e da sexualidade homossexual foram situadas entre sujeitos homossexuais numa esquina de prostituição e "pegação" de travestis e "montadas". Para as colaboradoras, elas se diferenciam dos "gays finos" que frequentam regularmente as festas eletrônicas sobralenses. Em seus relatos, esses gays se consideram másculos e "não se misturam" com bichas. Investigar como esses considerados "gays finos" interagem e engendram suas buscas amorosas e/ou sexuais nestes espaços festivos pode representar uma possibilidade de compreender as homossociabilidades sobralenses.

\section{REFERÊNCIAS}

BAUMAN, Zygmunt. Identidade: entrevista a Benedetto Vecchi. Trad. Carlos Alberto Medeiros. Rio de Janeiro: Jorge Zahar Ed.,2005.

BENEDETTI, Marcos. Toda feita: o corpo e o gênero das travestis. Rio de Janeiro: Garamond Universitária, 2005.

BUTLER, Judith. Problemas de gênero: feminismo e subversão da identidade. Rio de Janeiro: Civilização Brasileira, 2010.

ELIAS, Norbert; SCOTSON, John L. Os estabelecidos e os outsiders: sociologia das relações de poder a partir de uma pequena comunidade. Rio de Janeiro: Jorge Zahar Ed., 2000.

GOFFMAN, Erving. Ritual de interação: ensaios sobre o comportamento face a face. Petrópolis: Vozes, 2011.

HALL, Stuart. A identidade cultural na pós-modernidade. Trad. Tomaz Tadeu da Silva e Guacira Lopes Louro. 11. ed. Rio de Janeiro: DP\&A, 2006. 
PAIS, José Machado. Prefácio: Buscas de si: expressividades e identidades juvenis. In: ALMEIDA, Maria Isabel Mendes; EUGENIO, Fernanda (Orgs.). Culturas jovens: novos mapas do afeto. Rio de Janeiro: Jorge Zahar Ed., 2006. p.7-24.

PERLONGHER, Néstor Osvaldo. O negócio do michê: prostituição viril em São Paulo. São Paulo: Brasiliense, 1987.

PRECIADO, Beatriz. Testo Yonqui. Madri: Espasa, 2008.

QUEIROZ, Maria Isaura Pereira de. Relatos orais: do "indizível" ao "dizível". In: SIMSON, Olga Rodrigues de Moraes von (Org.). Experimentos com histórias de vida. São Paulo, Vértice, 1988. p.14-43.

WARNER, Michael. Introduction:fear of a queer planet. Social Text, Durham, n. 29, p. 3-17, 1991.

WOODWARD, Kathryn. Identidade e diferença: uma introdução teórica e conceitual. In. SILVA, Tomaz Tadeu da (Org.). Identidade e diferença: a perspectiva dos estudos culturais. Petrópolis: Vozes, 2008. p.7-72. 